Káñina, Rev. Artes y Letras, Univ. Costa Rica XL (1): 103-125, 2016 / EISSN:2215-2636

\title{
EL ESPAÑOL HABLADO POR LOS MALECUS: CARACTERIZACIÓN GENERAL Y RECONOCIMIENTO COMO VARIEDAD PARTICULAR ${ }^{1}$
}

\author{
The Spanish spoken by Malecus: general characteristics \\ and recognition as a particular variety
}

\section{Carlos Sánchez Avendaño*}

\begin{abstract}
RESUMEN
En este artículo se describe el español hablado por los malecus de Costa Rica con base en datos recogidos en los siglos XX y XXI, así como tomando en cuenta la edad, el poblado de procedencia y el tipo de bilingüismo del hablante. Se concluye que básicamente el español hablado por los malecus muestra tres tipos de fenómenos: a) variantes de desarrollo propias del proceso de adquisición del español como segunda lengua en edad tardía, exclusivamente en el caso de los ancianos; b) cambios lingüísticos con vigencia intergeneracional y explicables a partir del contacto prolongado entre el español y la lengua malecu; y c) rasgos de las variedades de español habladas por los grupos hispanos con los que los malecus han mantenido contacto intenso y prolongado durante distintos momentos históricos. Asimismo, se determina que los hispanocostarricenses de la región mayoritariamente consideran que existe una variedad de español hablada por los malecus, sobre todo los ancianos, mientras que los propios malecus opinan que este español "peculiar" es exclusivo de los mayores.
\end{abstract}

Palabras clave: malecu, español de contacto, interlengua, cambio lingüístico, etnolecto.

\begin{abstract}
In this paper, we describe the Spanish spoken by the Malecu people of Costa Rica. Our description is based on data collected in the 20th and 21st centuries, and it takes into account the age, hometown, and type of bilingualism of the speaker. We conclude that the Spanish spoken by the Malecu exhibits three salient characteristics, namely: a) existence of variants typical of the process of acquisition of Spanish as a second language at a later age, exclusively in the case of elders; b) occurrence of linguistic changes with intergenerational validity and explainable from the prolonged contact between Spanish and the Malecu language; and c) presence of features of the varieties of Spanish spoken by the diverse Hispanic groups with whom the Malecu have maintained intense and prolonged contact during different historical moments. In addition, we found that most of the Hispanic Costa Ricans in the region believe that the Spanish spoken by the Malecus is a variety of Spanish in its own right, still more differentiated from their Spanish in the case of older Malecus. Conversely, the Malecu themselves sustain that that this "peculiar" Spanish is exclusive of older speakers.
\end{abstract}

Key Words: Malecu, contact Spanish, interlanguage, linguistic change, ethnolect.

Universidad de Costa Rica, Profesor, Escuela de Filología, Lingüística y Literatura. Costa Rica

Correo electrónico: tocumarama@yahoo.es

Recepción:03/04/15. Aceptación: 05/08/15. 


\section{Introducción}

Los malecus (denominados habitualmente "guatusos" en los documentos históricos, crónicas de viaje de los siglos XIX y XX, y en miliples trajos acám XIX y XX, y en múltiples tra lingüístico y antropológico) constituyen uno de los pueblos originarios del territorio costarricense. La mayoría de la población (unos 500 individuos) reside en el cantón de Guatuso, provincia de Alajuela, actualmente en tres comunidades (denominadas "palenques"): $\mathrm{El}$ Sol, Tonjibe y Margarita.

Mientras su contacto con el grupo de lengua y cultura hispánicas fue sumamente esporádico y limitado al menos hasta la segunda mitad del siglo XIX (Constenla, 1988; Castillo, 2004), se puede suponer casi con total certeza que este se intensificó ya a mediados del siglo XX. En la actualidad, de acuerdo con el diagnóstico más reciente (Sánchez, 2011), su lengua autóctona se encuentra en un estadio intermedio del proceso de desplazamiento, el cual se manifiesta en el cese de la transmisión intergeneracional del idioma, la reducción de sus dominios de uso y un heterogéneo continuum de competencia bilingüe.

En cuanto a la competencia en español, si bien actualmente todos los malecus son bilingües malecu-español en diversos grados, bilingües malecu-español en diversos grados,
semilingües o (cuasi) monolingües en español, cabe destacar que existe correlación entre la edad y los fenómenos lingüísticos divergentes en su variedad de español. Así, en el habla de los ancianos encontramos múltiples rasgos de interlengua ("sistema intermedio caracterizado por los aprendizaje lingüístico" (Appel y Muysken, 1996, p. 125)) y una interferencia más evidente de la lengua malecu, mientras que en los jóvenes solamente perduran unos pocos rasgos de contacto con alguna vigencia, además de otros fenómenos relacionados con el habla de los grupos de hispanos con los que ha existido mayor contacto.

En el presente trabajo nos ocupamos de caracterizar de manera general el español hablado por los miembros de este grupo en cuanto a los rasgos fonológicos, léxicos y morfosintácticos más destacables, tema que no ha sido abordado a no ser en una brevísima alusión en Constenla (2005:71), quien se refiere al empleo del "pronombre usted con las formas verbales correspondientes al voseo" (como en el ejemplo '¿cómo estás usted?')

Nos centramos en describir los fenómenos detectados y, cuando nos resulta posible, los clasificamos dentro de tres tipos: posibles variantes de desarrollo en la adquisición del español como segunda lengua (fenómenos de interlengua), posibles variantes surgidas por el contacto de lenguas (esto es, cambios lingüísticos locales que se producen con participación de la lengua malecu), y formas vinculadas con variedades regionales del español. Nuestro acercamiento al problema es claramente de naturaleza exploratoria y cualitativa.

No elaboramos en este trabajo la argumentación necesaria para considerar que un fenómeno gramatical representa un cambio inducido por influjo de la lengua malecu, sino que únicamente proponemos tal caracterización. El ańlisis detallado al respecto se lleva a cabo El ańlisis detalado en otras tres monograflas (Sánchez 2015, a,) No obstante, si abordamos con detalle, a modo de ejemplo, dos fenómenos: el empleo de la preposición 'en' valor direccional o de destino, y el uso de 'dice/dicen' como marcador de evidencialidad en las narraciones.

Además, cabe destacar que asumimos una perspectiva comparativa con el propósito de poder llevar a cabo nestra descripción. Nuesto punto de referencia variedades de español habladas en el territorio costarricense sin contacto con una lengua amerindia, tal y como han sido descritas o documentadas, de forma global, en Agüero (2009), Arroyo (1971) y Quesada $\left(1990,1991,2009,2010^{2}\right)$ y en artículos monográficos que citaremos oportunamente.

\section{El estudio de las variedades del} español habladas por grupos

\section{indoamericanos}

En términos generales, en lo concerniente a la descripción de las variedades del español hablado en América, se puede afirmar que se ha pasado de la postura interesada principalmente en exponer cuál ha sido el aporte (sobre todo léxico, pero también de algún rasgo fonológico o morfosintáctico muy concreto) de las lenguas indoamericanas, como un todo o en regiones hispanohablantes específicas (véanse, por ejemplo, Alvar, 1996; Buesa y Enguita, 1992. ipsi 1994; Moreno Lipski 1994, Moreno de Alba, 1988; Quesada, 2000, Zamora y Guitart, 1982), a describir con detalle las variedades de español o fenómenos lingüísticos específicos surgidos por contacto de lenguas, particularmente en poblaciones históricamente bilingües.

En la actualidad, este segundo interés va en aumento. Desde los pioneros estudios de Germán de Granda acerca sobre todo, del español paraguayo pero tam ejemplo en de Granda (1994), han aparecido no solo múltiples monografías -que no citamos aquí por razones de espacio y de pertinencia-, sino también síntesis de publicaciones (por ejemplo, Blas, 2008; Klee y Lynch, 2009; Lipski, 1994), compilaciones que dan cuenta de variedades de todo el continente (Palacios, 2008) o parte de él (Olbertzy Muysken, 2005; Zimnnernann y Stolz, 2001; Escobar y Wolck, 2009) y teorizaciones que proponen explicaciones globales de los fenómenos documentados en diversas áreas (Palacios, 2011, 2013).

En el ámbito costarricense, no obstante, únicamente se ha analizado con detalle la variedad de español hablada por los bribris de la región de Salitre y Cabagra (Lininger, 1991) y, con menor detalle, se ha descrito el español hablado por los huetares actuales (Quesada, 1996). Aparte de estos trabajos, solamente se han publicado breves alusiones a rasgos particulares del español hablado por bruncas (Constenla y Maroto, 1979); bribris y bruncas (Constenla, 2005); y huetares, bruncas y noves (Quesada, 2008).

\section{Referencias sobre el españo \\ hablado por los malecu en el siglo XX}

A continuación echaremos un breve vistazo a exiguos y asistemáticos datos con que contamos del español hablado por los malecus en distintos momentos del siglo XX, según lo consignado en informes de personas que tuvieron algún contacto -esporádico o profundo- con ellos. Al principio, los viajeros solamente registraron sus impresiones. Así, Sapper (1942), en relación con su viaje de a "defectuoso". Para la segunda década del siglo XX, se infiere de lo escrito por Céspedes (1923) que había un gran número de bilingües, aunque muy probablemente con competencia limitada en español ("ya hoy casi todos hablan o se der en español", escribe Céspedes, 1923, p. 51-52)

Para la segunda mitad del siglo XX, ya toda o la mayor parte de la población podía comunicarse en español, según lo informado por Ballestero (1952), Porras (1959), Bozzoli (1969) y Constenla (1975), pero para conocer cómo era este dependemos casi exclusivamente de los diálogos, oraciones y palabras que reproducen Céspedes (1923), Ballestero (1952), Porras (1959) y Salguero (1969) en sus relatos.

De acuerdo con lo que se puede interpreta de la crónica de Céspedes (1923), el español de los malecus para la segunda década del siglo XX habría sido una variedad simplificada y con una fonología y gramática altamente desviantes en relación con la variedad sin influjo indígena, y con muchos vocablos malecus insertados. Es decir, sería una lengua en estado de adquisición no consumado y con rasgos de variedad de desarrollo (interlengua), una variedad "con palabras guatusas o como los chinos que hablan español", según la caracterización explícita de Céspedes (1923, p. 67)

En lo tocante a la morfosintaxis, el español de los malecus de la época se caracterizaría po la tendencia a emplear el infinitivo o una forma verbal de tercera persona ('nosotros indios, chi, chi, cuando ver culebra cortar cabeza para no picar...ellas tener cólera por no hacer pronto y matar el muchacho' por 'nosotros los indios, lebra, le cortamos la cabeza para que no nos pique.. a ellas les da cólera por no hacerlo pronto y matan al muchacho'; 'Dame puro, Saka y volver contar' por 'dame un 
puro, hermano, y te vuelvo a contar la historia' (Céspedes, 1923, pp. 67-68); 'SI, SI, me decía el guatuso de la vara, chiquitos atollar pa no pica zancudo' por 'los niños se untan manteca de cacao para que no los piquen los zancudos' (Céspedes, 1923, pp. 68); 'Sí, sí, decía el indio, llamar paitat ochap-paca, porque aquí morir muchos indios y muchos muerras' por 'sí, sí, decía el indio, se llamaba ya se murió el hombre, porque aquí murieron muchos indios y muchos ogros' (Céspedes, 1923, pp. 82)).

En lo que respecta al léxico, se habrían insertado cada tanto palabras y frases completas en malecu ('Chi, chi, indio, cré todo, naiála pun por 'todo, todo, el indio cree todo, ??' (Céspedes, 1923, pp. 67-68)); 'matar otra india con palo de chopo aquí en na-córi' por 'mató a otra india con un palo de rifle aquí en el pecho' (Céspedes, 1923, pp. 71-72). Y en lo relativo a la fonología, se presentarían elisiones de vocales, simplificación de grupos vocálicos y realización de /g/ como [h] ('no olvidar treme chopo, pañelo, ropa' por 'no olvide traerme un rifle, un pañuelo y ropa' (Céspedes, 1923, pp. 73); 'pañelo colorao' por 'pañuelo colorado' (Céspedes, 1923, pp. 89); 'el pejar mucho' por 'él me pega mucho'; 'ducado' por 'educado' (Céspedes, 1923, pp. 71-72)).

Según lo que consignan los únicos autores de mediados del siglo XX que en sus relatos insertan muestras del español hablado por los malecus (Ballestero, 1952; Porras, 1959), se nota que pervivían al menos el uso del infinitivo en sustitución de cualquier conjugación verbal ('indio ser inteligente, como vos' por 'el indio es inteligente, como vos' (Porras, 1959, p. 52), ‘Qué querer vos saber?' por '¿qué querés saber vos?’ (Porras, 1959, p. 78)), y la elisión de vocales o incluso sílabas iniciales de palabra ('estar ferma ...va morir seguro' por 'está enferma va a morir seguro' (Ballestero, 1952, p. 157), 'maestro recho' or 'maestro arrecho' (Ballestero, 1952, pp. 157))

Para finales de la década de 1960, Salguero (1969), en un artículo de periódico, intenta reproducir literalmente el relato de un malecu acerca de sus viajes a Tilarán para vender pejibayes. En este, el rasgo más característico es la aparición de verbos en infinito ('si el hombre ser fuerte, llevar 800 pejibayes al hombro', 'si ser débil', 'entonces nosotros no vender', 'nadie querer comprar'). Además, aparece un 'verbo conjugado en singular persona plural ('llegamos y dice a la gente'), una omisión de un clítico de objeto directo de tercera persona ('para no botar' por 'para no botarlos'), una asignación de género nominal no canónica ('la pejibaye') y una discordancia de género en un grupo nominal ('la gente blanco').

Posteriormente, dejan de consignarse rasgos específicos del español hablado por los malecus. Solo se aludirá de modo muy general y vago a su variedad divergente con respecto a la variedad monolingüe sin influjo indígena, si bien ya aparecen matizaciones en cuanto a la edad del hablante: "En las comunidades guatusas (...) el castellano de los viejos es difícil de entender" (Bozzoli, 1969, p. 37).

\section{El español hablado por los malecus \\ en la actualidad}

A continuación sistematizamos los principales rasgos fonológicos, morfosintácticos y léxicos particulares del español hablado por miembros del pulo malecu a patir de neesto miem en ocho entrevistas individuales y doce grupos de discusión, que en conjunto suman unas veinte horas y media (1233 minutos) de grabación sobre el tema del desplazamiento de la cultura tradicional y la lengua vernácula. A este corpus se aúnan nuestras anotaciones de rasgos aparecidos conversaciones de muy diversa temática ${ }^{4}$.

Son dos las variables que parecen tener relación tanto con el tipo de bilingüismo como con los fenómenos de variación en el españo hablado por los miembros de este pueblo: la comunidad de origen y la generación. En el siguiente cuadro se resumen las características demosociales y lingüísticas de los hablan de los que se obtuvo el corpus de entrevistas y grupos de discusión.

TABLA 1

Distribución de hablantes por comunidad y generació

\begin{tabular}{|c|c|c|}
\hline Comunidad & Grupo generacional & Cantidad de participantes y tipo de bilingüismo \\
\hline \multirow[t]{4}{*}{ Margarita } & Habla de jóvenes & $\begin{array}{l}17 \text { jóvenes con edades entre los } 13 \text { y los } 30 \text { años. Incluye jóvenes } \\
\text { que declaran solo competencia receptiva (amplia o reducida) o } \\
\text { competencia productiva limitada. }\end{array}$ \\
\hline & Habla de adultos & $\begin{array}{l}10 \text { adultos con edades entre los } 32 \text { y los } 40 \text { años. Incluye adultos que } \\
\text { declaran ser bilingües relativamente equilibrados o con competencia } \\
\text { productiva disminuida. Algunos son bilingües simultáneos. }\end{array}$ \\
\hline & $\begin{array}{l}\text { Habla de ancianos con bilingüismo } \\
\text { equilibrado }\end{array}$ & $\begin{array}{l}2 \text { ancianos con edades entre los } 60 \text { y los } 70 \text { años. Declaran } \\
\text { competencia bilingüe relativamente equilibrada. Son bilingües } \\
\text { sucesivos. }\end{array}$ \\
\hline & $\begin{array}{l}\text { Habla de ancianos con el malecu } \\
\text { como lengua dominante }\end{array}$ & $\begin{array}{l}3 \text { ancianos con edades entre los } 65 \text { y los } 80 \text { anos. Declaran } \\
\text { competencia limitada en español. Claramente son bilingües } \\
\text { sucesivos. }\end{array}$ \\
\hline \multirow[t]{3}{*}{ El Sol } & Habla de jóvenes & $\begin{array}{l}5 \text { jóvenes con edades entre los } 17 \text { y los } 30 \text { años. Declaran } \\
\text { competencia productiva limitada, pero receptiva desarrollada }\end{array}$ \\
\hline & Habla de adultos & $\begin{array}{l}4 \text { adultos con edades entre los } 33 \text { y los } 36 \text { años. Declaran desde } \\
\text { competencia activa desarrollada hasta limitada (por adquisición } \\
\text { incompleta). }\end{array}$ \\
\hline & Habla de adultos mayores & $\begin{array}{l}2 \text { adultos mayores con edades entre los } 54 \text { y los } 57 \text { años. Declaran } \\
\text { competencia equilibrada en ambas lenguas, pero claramente son } \\
\text { bilingües sucesivos. }\end{array}$ \\
\hline Tonjibe & Habla de jóvenes & $\begin{array}{l}11 \text { jóvenes con edades entre los } 14 \text { y los } 26 \text { años. Declaran desde } \\
\text { competencia productiva limitada hasta desarrollada. Todos son } \\
\text { bilingües receptivos. }\end{array}$ \\
\hline & Habla de adultos & $\begin{array}{l}6 \text { adultos con edades entre los } 33 \text { y los } 50 \text { años. Se trata de } 4 \\
\text { bilingües equilibrados, pero sucesivos, y de } 2 \text { con bilingüismo sobre } \\
\text { todo receptivo en malecu. }\end{array}$ \\
\hline & Habla de ancianos & $\begin{array}{l}4 \text { ancianos con edades entre los } 58 \text { y los } 64 \text { años. Declaran } \\
\text { competencia productiva limitada en español. Claramente son } \\
\text { bilingües sucesivos. }\end{array}$ \\
\hline
\end{tabular}

Como señalamos en Sánchez (2011) en cuanto a los perfiles sociolingüísticos por grupos generacionales, la terminologia concerniente a los tipos de bilingüismo que empleamos describe de manera aproximada el momento de adquisición (bilingüismo sucesivo y bilingüismo simultáneo) y la competencia lingüística (bilingüismo equilibrado y bilingüismo subordinado con el malecu o el español como lengua dominante), según lo reportado por los individuos.

Para la presentación de los resultados, se aludirá al grupo etario y se incluirán detalles sobre el tipo de bilingüismo y la comunidad de origen en los casos en los que se considere pertinente. Para mayores detalles, remitimos a estudio pormenorizado en Sánchez (2011). La 
importancia de tales perfiles sociolingüísticos es puesta de relieve por Blas (2008) como requisito para poder llevar a cabo un acercamiento apropiado a los fenómenos de contacto de lenguas.

De acuerdo con la categorización generacional ad hoc que formulamos a partir de nuestro conocimiento de las circunstancias de vida del pueblo malecu y su devenir histórico (Sánchez, 2011), el bilingüismo de los adultos mayores (de aproximadamente 50 años) y los ancianos (mayores de 65 años) se puede caracterizar como sucesivo, con el malecu como idioma dominante.

En nuestros datos se encuentran, sin embargo, dos grupos: en las personas mayores de 70 años en Margarita y en las mayores de 55 en Tonjibe, se halla una variedad de español caracterizable como interlengua con variantes de desarrollo fosilizadas o inestables, las cuales incluyen múltiples discordancias, construcciones morfosintácticas idiosincréticas y neologismos léxicos, mientras que en los individuos menores a estos rangos de edad en las respectivas comunidades no se aprecian estos fenómenos, solo esporádicamente o solo cuando se trata de cambios por contacto con vigencia intergeneracional.

Los adultos (personas de entre 35 y 50 años) y los adultos jóvenes (individuos de entre 30 y 35 años), de acuerdo con nuestra tipología ad hoc, representan la generación de transición. Los mayores de 35 años en Tonjibe declaran que su bilingüismo fue sucesivo, con el malecu como lengua materna, mientras que en muchos otros se trata de un bilingüismo simultáneo, con diversos desarrollos de la competencia productiva en un continuum de bilingüismo sumamente heterogéneo, dependiendo de la biografía de cada sujeto.

La heterogeneidad de la situación sociolingüística hallada en el grupo anterior continúa en el grupo de jóvenes (con edades entre los 14 y los 30 años), pero con una evidente tendencia a la reducción de la competencia productiva en malecu, el aumento del semilingüismo e incluso la paulatina merma de la competencia receptiva, hasta llegar al (cuasi) monolingüismo. No obstante, el bilingüismo relativamente equilibrado o al menos la capacidad productiva desarrollada en malecu es más común entre los jóvenes de Tonjibe que en los muchachos de las otras dos comunidades.

\subsection{Rasgos fonéticos}

De la generación de los ancianos recogimos datos de solamente un hablante cuyo español parece aproximarse, en lo fonético, al del habla representada en la exigua documentación del siglo XX realizada por Céspedes (1923) y Ballestero (1952) (y a quien denominamos el "hablante más innovador"). Así, en su habla se registran la realización de [h] del fonema /g/ y varias elisiones de vocales y sílabas iniciales de palabra.

Ejemplos del primer fenómeno son los siguientes: 'tamuja [ta'muha] de dulce' por 'tamuga [ta'muya] de dulce ', 'Cartajo [kar'taho]' por 'Cartago [kar'tayo]', 'lleja ['Jeha]' por 'llega ['Jeya]'. Ejemplos del segundo fenómeno son: 'se fendió' por 'se defendió', 'ramientas' po ' 's 'marrar' por 'amarrar' 'humado' por 'ahumado', 'costado' por 'acostado' ('a veces yo estoy costado en la hamaca ahí'), 'filado' por 'afilado' ('con buen filado cuchillito'), 'solea' por 'asolea' ('ellos lo solea así puño [de cacao]') A estos se suma la frecuente aspiración y elisión de /s/ implosiva ('pobres loh amigos míos', 'puede ser que solamente es el padre de elloØ').

Además, en este hablante se hallan fenómenos no reportados y que únicamente hemos encontrado en su habla: sonorización de $/ t /$ (particularmente en la palabra 'danta' pronunciada como ['danda] en varias emisiones, si bien aparece en alternancia con la pronunciación ['danta] $)^{6}$; [t] por [s] (en [ta'ino] por [sa'ino] 'saíno', aunque también pronuncia [sa'hino]), inserción de /e/ paragógica (en [sata'nase] por [sata'nas] 'Satanás': 'ahí nomás me puso el el colmillo ese satanase') $)^{7}$.

De todos estos fenómenos, solo la elisión de /a/ inicial de palabra se encuentra en el habla de otros ancianos de Margarita y Tonjibe, como se aprecia en los siguientes ejemplos: 'ellos le (a) prendieron en la escuela así en español', 'estoy (a)costumbrada hablar así en español', 'yo me (a)prendí todo en el malecu', 'los hombres (a) brazando con los hombres', 'no es tanto de (a) prender', '(a)costumbrar todo hablar en chiúti', 'nadie me (a)yuda', '(a)guacate', '(a)somar', '(a) borigen'. Este fenómeno es posible escucharlo incluso en el habla de algunos jóvenes bilingües: 'las matitas estaban todas (a)rrancadas', '(a) marrar', '(a)guantar', 'para que usted (a)rranque la yuca', ‘y ya (a)rrancaron la yuca?'. No obstante, está ausente del habla de la mayoría de los adultos y jóvenes, independientemente de su edad y competencia en la lengua malecu.

De los rasgos citados, la aspiración y elisión de /s/ implosiva es el único rasgo encontrado en el hablante más innovador que muestra vigencia en el habla de todas las generaciones. Asimismo, si bien conforme disminuye la edad es posible escuchar más realizaciones fricativas [I] del fonema $/ \mathrm{r} /$, parecen ser mucho más frecuentes las vibrantes múltiples [r] incluso entre los más jóvenes. En el habla de los ancianos, esporádicamente también hemos escuchado pronunciaciones fricativas sordas de /b/ (como en [so' $\phi a r]$ 'sobar')

Aunque no siempre se pueda determinar con total certeza el origen de estos rasgos, podemos adelantar algunas hipótesis. En primer lugar, habría que considerar la interferencia fonológica del malecu. Así, la realización $[\phi]$ de $/ b /$ se debe a que $[\beta]$ es alófono de $/ \phi /<f>$ en malecu y varía con la realización $[\phi]$ a veces en distribución complementaria y a veces en forma relativamente libre (Constenla, 1998), de modo que hay hablantes que en alguna ocasion en español estarían tratando el sonido $[\beta]<\mathrm{b}, \mathrm{v}>\mathrm{del}$ español como alternante de $[\phi]$.

Por su parte, la realización $[\mathrm{h}] \mathrm{de} / \mathrm{g} /$ posiblemente se debe a la inexistencia del fonema /g/ (y de los sonidos [g] y [y]) en el sistema fonológico patrimonial malecu. De hecho, en los pocos hispanismos con el fonema /g/ que entraron en malecu y que se adaptaron a la fonología de esta lengua, $/ \mathrm{g} /$ se reinterpretó como una nasal velar $/ \mathrm{n} /$, el sonido articulatoriamente más cercano en malecu (así ocurre, por ejemplo, en /nai:na/ 'gallina'). Empero, es curioso que /g/ no se realice, ni en los ejemplos documentados por los viajeros ni en nuestros datos, como [n] sino como [h].

Es posible que los otros fenómenos hallados en el habla del anciano más innovado hayan sido más comunes, pero no están documentados ni hemos tenido ocasión de registrarlos en otros hablantes ancianos. Por otra parte, pese a que en este las elisiones de vocales y sílabas iniciales de palabra son variadas, en los demás ancianos y personas en los que se documenta este fenómeno solamente se elide el segmento /a/. Nada hallamos en la estructura fonológica del malecu que permita inferir que se trata de una interferencia, pues en este idioma existen palabras que inician con /a/ y que muestran una estructura silábica idéntica o muy parecida a la de las palabras en español en las que se ha registrado la caída.

Agüero $(2009$, p. 31) describe para el habla costarricense (como "vulgarismo", sin especificación de variables de ningén tipo) la aféresis vocálica o silábica, con ejemplos como '(a)cequia', '(a)lacena', '(ha)maca' y '(a)urora'. Sin embargo, ni Arroyo (1971) ni Quesada (1990 2009,2010 ) se refieren a este rasgo en particular, si bien este último autor documenta algunas reducciones de grupos vocálicos. Es posible, en todo caso, que se trate de un fenómeno relacionado con el habla campesina de la región ${ }^{8}$, aunque no es claro por qué afecta en el presente únicamente a las palabras que inician con $/ \mathrm{a} /$ dado que Agüero documenta también aféresis de otras vocales.

La aspiración y elisión esporádicas de /s/ implosiva muy posiblemente se vincula con el habla nicaragüense y del noroeste de Costa Rica, pues en el Valle Central lo regular es la realización fricativa alveolar (Quesada, 2009) y el fenómeno no se encuentra en el idioma malecu, el cual realiza como fricativas alveolares todas las /s/ (Constenla, 1998), mientras que en Nicaragua y la región noroeste de Costa Rica es muy común la aspiración y la reducción total de /-s/ (Lipski, 1994; Quesada, 1991). Es decir, estaríamos en este caso ante la pervivencia de un rasgo propio del primer grupo hispánico de contacto intenso ${ }^{9}$, pues en la segunda mitad 
del siglo XIX el territorio malecu fue invadido por huleros nicaragüenses $-\mathrm{y}$ probablemente guanacastecos-(Castillo, 2004; Constenla, 1988) y antes de las décadas de 1970 y 1980 eran sobre todo grupos de origen nicaragüense quienes se habín asentado en la región (Hernández, 1996; Ugalde, 1973).

Finalmente, la realización vibrante múltiple $[\mathrm{r}]$ de /r/ también se puede vincular con el habla nicaragüense y del noroeste de Costa Rica (Lipski, 1994; Quesada, 1991), pues en el Valle Central la realización normal actualmente es la fricativa apicoalveolar []$_{1}^{10}{ }^{10}$ (Agüero, 2009; Umaña, 1990); sin embargo, con toda probabilidad en este caso la fonología del malecu actúa para reforzar este rasgo, puesto que esta lengua tiene en su repertorio un fonema /r/ muy frecuente, realizado como [r]. Valga insistir en que son únicamente estos dos últimos rasgos fonéticos los que muestran verdadera vigencia intergeneracional en el presente.

\subsubsection{Rasgos morfosintácticos}

Los rasgos morfosintácticos son mucho más abundantes y algunos de ellos muestran una vigencia intergeneracional mayor que los fenómenos de variación fonética. Entre estos sobresalen las discordancias verbales y nominales, las mezclas entre formas de voseo y de ustedeo, $y$ algunos cambios en el empleo de las preposiciones 'para' y 'en'.

Las discordancias entre el sujeto y el verbo regido por este son múltiples entre los ancianos de las tres comunidades. A continuación consignamos algunos ejemplos de ancianos de Margarita con español subordinado al malecu: 'nosotros es malecu', 'yo escucha / ellos sabe', 'maestros no está enseñando en eso', 'ellos no creció aquí en mi casa', 'yo opina', 'ellos tiene la culpa', 'yo no lleva cuenta', '¿no ve que todos tiene buena casa?', 'yo ha matado', 'lo que ha hecho aquí estos paisanos míos', 'tiene razón que puso bravo / este / los nicaragüenses', 'yo vive aquí'. Si bien se puede apreciar de los "yojive aqu'. Si bien se pue do aprecine de los predomina la conjugación en tercera persona singular, también es común la aparición de los verbos en forma infinitiva: 'mis hijas todas se se: / otros juntar otros casar', 'ya yo no andar monte

Entre los adultos mayores de Margarita con bilingüismo equilibrado también son frecuentes estas discordancias, pero únicamente en la dirección de neutralizar la distinción entre tercera persona plural y tercera persona singular: 'los guaimíes / sí mantiene su cultura', 'lo vio los chiquitos', 'no se lo voy a decir cuál es / los métodos que nosotros utilizamos ', 'hoy cuánto me gustaría que fuera todos esos chiquitos', 'ahora sale muchos indígenas blancos'.

De personas ancianas de Tonjibe encontramos ejemplos como los siguientes: 'yo nació aquí', 'yo habla con mis hijas', 'ellos no sabe casi / el malecu', 'solo ustedes habla en en el español', '¿pero qué va hacer yo?', 'los jóvenes y los pequeñitos / los güilas / habla todo en: en: español', 'cuando yo le dijo a ellos', 'con esos yo conversa', 'ellos sabe', 'cuando yo tuvo', 'qué es lo que me dijo ellos', 'ellos yo tuvo', 'que es lo que me dijo ellos', 'ellos no cont,', 'yo no me pudo aprender, bien la palabra', 'cuando venia los maestros', 'ya los mayores ya no existe / ya se había muerto todos'. En este caso también aparecen verbos en infinitivo ('en vez en cuando me enreda cuando hablar en: español').

También en el corpus de las personas adultas mayores de El Sol documentamos varias discordancias con tendencia clara hacia la conjugación en tercera persona singular: 'a veces ha nacido / los pobrecitos niños / imperfectos', 'todos los animales que hay es creado', 'para que otros viva', 'a mí se me olvidó muchas cosas', 'cuando viene esos gringos ojos celestes', 'yo es la única', 'como los hijos míos que es cruzado', 'ellos entiende muy bien'.

En la generación de adultos de los tres poblados, casi todos los casos documentados de discordancias de este tipo son producidas por neutralización entre la tercera person singular y plural: 'ellos no le entiende a $\mathrm{m}$ mamá', 'las vulgaridades en en malecu es es demasiado vulgar', 'donde está todas las palabras', 'cuando dice los muchachos', 'venía dos borrachos', 'hay palabras que que ya se extinguió', 'las señoras / también habla bastante', 'ellos mantenía la lengua', 'quiere que nuestros hijos se supere'. Lo mismo ocurre en el habla de los jóvenes de las tres comunidades: 'no le salía las palabras a ella', 'se pierde todas las tradiciones', 'hay varias cosas que que no va ir en el libro', 'iba unas gentes allá', 'muchas personas dice'.

Un tipo particular de discordancia sujetoverbo en el español hablado por los malecus que merece tratarse por separado es la concordancia ad sensum con el sustantivo colectivo 'gente' (sustantivo morfológicamente singular pero con sentido plural y verbo morfológicamente en plural). Para este fenómeno no se halla una correlación evidente entre las variables de comunidad y grupo generacional con respecto a la mayor o menor frecuencia, de modo que constituye uno de los rasgos de variación con mayor vigencia intergeneracional.

De la generación de ancianos tenemos ejemplos como: 'la gente pero me aplaudieron me aplaudieron', 'la gente no saben hacer eso', 'la gente / cazan hoy en día', 'la gente / no quieren caminar de aquí allá / la gente creen que andar en en carro / eso es vida', 'otra gente vinieron', aquí pasaban mucha gente y me decían', 'para que la gente digan', 'se quedaron admirada esa gente'.

De la segunda generación tenemos ejemplos como 'esta gente no le hablan' 'la mayoría de la gente adulta se han dedicado a , extranjera o la gente de la misma Costa Rica / dicen eso', 'la gente tienen que saberlo', 'ya mucha gente no van a comer eso', 'la gente pagaron [el agua]', 'que se den cuenta la gente que él nos manipula'. De la generación joven documentamos, entre otros, los siguientes ejemplos: 'salen gente vestidas / vestidos de indio', 'la gente saben de que s', 'llegan gente que no son malecu', 'ahi es la gente se burlan de ellos', 'anduvieron gente del Ministerio de Cultura', 'la gente llegaron'

Otro tipo de concordancia particularmente llamativo en el español malecu es aquel correspondiente a los verbos de dativo como 'gustarle a uno algo', 'avergonzarle a uno algo' 'Tomo argumentos nucleares el sujeto indirecto, en lugar de sujeto y objeto directo como los centrales y el objeto indirecto solo en verbos ditransitivos). En este caso, en el español malecu frecuentemente el verbo se hace concordar con el argumento dativo y no con el sujeto.

Algunos ejemplos del discurso de los ancianos son: 'y las muchachas también / ellas le gustan también [tener amistades]', 'si le interesan no se va a perder [el malecu a los jóvenes]', 'muchos le dan vergüenza' [por 'a muchos les da vergüenza'], 'sí se puede aprender más el malecu pero le van a costar porque ellos están aprendiendo más en español', 'a veces les agarran eso [a los blancos decir cosas en malecu]', 'mientras que mis hijos no le gustan eso', 'a ellos [los bebés] le quedaron la ropita', 'a ellos le daban asco comer no sé qué clase de manteca'

En la segunda generación hemos registrado ejemplos como: 'los jovenes / le dan vergüenza de de que los llamen indios', 'hay muchos jóvenes que no están interesados / le dan vergüenza', 'por supuesto que le interesaban [aprender el malecu a los que llegaban]', 'porque hay muchos jóvenes que no le gustan / le dan vergüenza', 'ellos le daban risa [por 'a ellos les daba risa']', 'a ellos se les han hecho difícil venir a dejarlo', 'ellas no le gustaron cuando su mamá vino'

Ejemplos en el habla de personas jóvenes son los siguientes: 'solo que no / no les den vergüenza hablar [a mis hijos]', 'ellos le van a dar miedo [ir a estudiar a San José]', 'mis hermanillos / les gustan molestarlo', 'hay chiquillos que le gustan participar', 'hay muchos jóvenes / que le gustan ir', 'hay algunos que no / que ni le interesan ya / el hablar', 'los jóvenes / le dan vergüenza / sí que: / yo sí que digo que le dan vergüenza', ' pero ellos no le interesan / o sea / en sí sí ellos no le interesan nada', 'hay muchos que no no le gustan ya el malecu', 'le dan vergüenza de ser malecu [a muchos jóvenes]', 'ya los ancianitos les cuestan mucho el / el español', 'a los turistas le gustaron el mafuriséca [platillo tradional] / le encantaron'.

En cuanto a la categoría verbal de modo, hemos registrado unos pocos ejemplos de 
neutralización entre el indicativo y el subjuntivo en el habla de los ancianos, en cláusulas en las que el español no malecu normalmente utilizaría indicativo y no subjuntivo ('en lo que tiene: hijos con gente blanco / de pequeñitos no les hable en malecu' con el sentido de 'las mamás que tienen hijos con gente blanca y de pequeñitos no les hablan en malecu a los hijos'; 'después / otro me diga sí sí habla' por 'después otro me dice/me dijo sí sí habla') o, a la inversa, en las que se emplearía el subjuntivo en lugar del indicativo ('para que los güilas entienden el malecu' por 'para que los güilas entiendan el malecu', 'para que no se pierde la idioma de nosotros' por 'para que no se pierda el idioma de nosotros'). En las demás generaciones no se encuentra este fenómeno.

En el habla de los ancianos también se encuentran algunas conjugaciones verbales en las que un verbo regular se interpreta como perteneciente a algún paradigma irregular (por ejemplo, 'yo me apriendí' o 'aprienden solo para estar', en los que 'aprender' se toma como un verbo del grupo de los que diptongan la vocal acentuada, en el primer caso aplicando incluso la regla de diptongación cuando no correspondería tampoco) o un verbo irregular se regulariza (por ejemplo, 'son matancines de iguana que hacimos')

En las demás generaciones, en la mayoría de los casos, únicamente aparecen conjugaciones que podrían catalogarse como no normativas, pero presentes en el habla de muchas personas no malecus, sobre todo en el de aquellas cuyos usos no muestran tanta influencia de la presión prescriptiva (escolar y social) (Agüero, 2009; Arroyo, 1971; Quesada, 2009). En los adultos registramos casos como: 'Tonjibe ha rompido las reglas de del juego', 'Tlgunos de avergo de hablar el malecu', 'en Margarita me dijieron que estaban sacando', 'si usted no se interesara / yo no te: / fuera contado'. En los jóvenes documentamos: 'entonces se ponieron a reír', 'lo que cambea es cómo se pronuncia'.

Aparte de los anteriores, dos fenómenos propios del habla popular hispanocostarricense (A 1971; Quesada, 2009) se encuentran en todas las generaciones: 'haiga' por 'haya' y la enclisis de -n en los verbos pronominales y tras clítico de objeto. En los ancianos se escucha: 'para que haiga esa', 'dígamen en chiúti'. En los adultos documentamos: 'mientras haiga alguien con quien yo pueda estar hablando", "olvídesen ustedes se lo juegan", "yo le digo al extranjero " "preguntenlen a ellos", "hag "preguntenlen a ellos", "hágansen mujeres', 'sientésen aquí', 'adonde iban a bañarsen / era al río'. Y en los jóvenes registramos: "estoy orgulloso de que / mi hermana se haiga juntado', 'les digo "váyansen a andar ustedes", vulgaridades / díganlen a él".

En lo que respecta a la concordancia entre elementos nominales, cabe destacar que las discordancias de género y número entre el sustantivo nuclear y sus modificadores son sumamente frecuentes en el habla de los anciano de Margarita con el malecu como lengua dominante, como se aprecia en los siguientes ejemplos: 'con todo la grupo', 'está todo revuelto con gente blanco', 'todo familia muerto', 'aqui todo gente hace', 'agarró todo tierra aquí', ' 'gente bravo viene a me indígenas', 'e jodido danta / muy bravo'

No obstante, también en el habla de lo ancianos con bilingüismo equilibrado de esta comunidad se hallan múltiples discordancias: 'toda Ø esas cosas', 'con cebolla picado', 'hoy en día que está globalizado las cosas'. En el habla de los ancianos de Tonjibe y de los adultos mayores de El Sol también se documentan numerosas discordancias nominales: 'todo la gente', 'solo puro mujeres', 'los gente blancos', 'todo la gente', 'iqué cosa más lindo!', 'ese es la comida favorito'. En la segunda generación disminuye drásticamente la frecuencia del fenómeno, si bien todavía se documentan ejemplos: 'mi papá no enseño bastanteØ cosas' 'son pocos las personas', 'todo la cultura'. Finalmente, en el habla de los jóvenes, registramos varias discordancias en los jóvenes de Tonjibe: 'ese ritmo de las person blanca", 'qué ricaØ iguanas', 'mis hermanos no son capazØ de dejarse una chiquilla así'.

$\mathrm{La}$ lengua malecu no codifica gramaticalmente nada parecido al género del español y tan solo algunas distinciones de la categoría de sexo en los humanos están lexicalizadas. Además, no tiene un sistema de concordancia nominal en cuanto al número como la del español. Así las cosas, es muy probable que las discordancias nominales de género y número documentadas en el español malecu estén vinculadas a la influencia de la gramática del malecu.

En lo que respecta a las preposiciones, en el habla de los ancianos se hallan muchos empleos idiosincráticos: 'a veces yo hablarle entre ellos' por 'a veces yo les hablo a ellos', 'tal vez me ayudan aquí nosotros en- entre indígenas' por 'tal vez nos ayudan aquí a nosotros los indígenas', 'yo se lo he manifestado con muchos / amigos' por 'yo se lo he manifestado a muchos amigos', 'yo me doy cuenta en eso' por 'yo me doy cuenta de eso', 'yo creo que ha influido muchísimo por el mestizaje de los malecu con los blancos' por yo creo que ha influido muchísimo el mestizaje de los malecus con los blancos'.

Los únicos usos preposicionales particulares del español hablado por los malecus que se encuentran en el habla de los ancianos y que mantienen vigencia en las demás generaciones son el empleo de 'para' para introducir el objeto indirecto y de 'en' para indicar dirección o destino, si bien en ambos casos la frecuencia de aparición disminuye marcadamente conforme se revisan los datos del habla de los ancianos con respecto al habla de los jóvenes.

En lo que respecta al objeto indirecto introducido con 'para' en el español malecu, hemos documentado los siguientes ejemplos en el habla de personas ancianas de los tres poblados: ¿cómo yo voy a / me- mentir para usted que yo soy gente blanca?', 'cuando lo habla / para otra gente' (con el sentido de 'cuando le hablo a otra gente'), 'yo habla siempre para ellos', "hable para Dios', 'su finca lo venden / para otro', 'yo para Dios', 'su finca lo vende / para oto', 'yo habla en m', 'c cu para usted', 'yo habla todo para mis hijas', 'el maestro está dando clase para los güilas', 'yo le estaba contando así en malecu para ella', 'va a darle agua para bestia', 'le voy a dar para ella', 'cuéntele usted para el', 'Marta ya no habla para Lucía', 'yo le estaba contando así en malecu para ella', 'a todos le di consejos para ellos', 'no lo va a dar para Marta', 'yo estoy orando para Dios', 'cuida el bebé para ella'.
En el habla de los adultos, registramo los siguientes ejemplos: 'hay bastantes madre que no quieren ahorita que los niños reciban malecu / porque o sea para ellos les cuesta', '¿y usted no regala adornitos para otra gente?', 'm mamá dijo para un montón de gente', 'lléveselo para Marta [el bebé]'. También documentamos

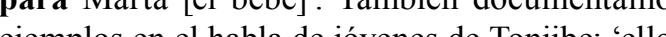
onjibe: 'ellos piensan que uno lo va a vender para
'ella lo vendió para otra compañera'.

La otra preposición que muestra un empleo sistemático particular en el español malecu distinto al español costarricense no malecu- es 'en' con valor de dirección o de movimiento hacia un destino o de término del movimiento Este uso sí muestra mayor conservación que e anterior en las generaciones jóvenes. Analizamo este fenómeno con detenimiento más adelante.

En el español malecu es común escucha formas verbales de ustedeo mezcladas con forma de voseo en una misma cláusula, mientras que en el español costarricense no malecu solamente se encuentran estas alternancias en cláusulas distintas. Los siguientes son ejemplos del corpus de ancianos: 'enseñale a su nieta', 'usted venís en un bus', 'que te dijera a usted', 'ya es hor de que usted te pongás a escribir', 'estás loco usted', 'usted me vas a creer', 'usted no me va a callar', 'yo te digo a usted', 'si usted hablás en malecu', 'ya estás rematado usted', 'qué es lo que tenés usted?'.

En el corpus de adultos encontramos los siguientes: 'su papá nunca te enseñó hablar en malecu', 'te hablará a usted en español', 'cuando usted me contastes', 'usted tuviste que auxiliar', '¿usted te casarías con una persona que no te gusta?', 'solo para complacerte a usted', '„para qué usted me pediste eso?', 'como te dije yo a usted', 'el tonto sos usted', 'cquićn sos usted?',

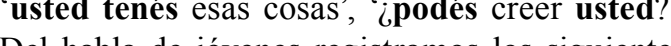
Del habla de jóvenes registramos los siguientes ejemplos: 'yo te puedo estar diciendo a usted', 'eso no te incumbe a usted', 'usted vas a decir', 'te tenemos en la mira a usted', 'no te estoy molestando a usted', 'yo te conozco a usted'.

En síntesis, las diversas discordancias verbales $y$ nominales pueden interpretarse como fenómenos de interlengua en los ancianos (a 
veces como resultado de la interferencia de a lengua materna y a veces como desarrollos idiosincráticos propios del proceso de adquisición) y como probables fenómenos de contacto en los adultos y jóvenes, en especial si pensamos que sobre todo muestran vigencia intergeneracional la concordancia $a d$ sensum con 'gente' y la concordancia con el objeto indirecto directo (o, mas precisamente, con el argumento que codifica el participante experimentador) en los verbos de dativo.

En cuanto a los preposiciones, vemos que los usos idiosincráticos tambièn tienen su origen en el proceso de desarrollo de la adquisición de la lengua y están relegados, por tanto, al habla de los ancianos, mientras que el empleo de 'para' como introductor de objetos indirectos y de 'en' con el valor d no pervive parcialmente en el habla de las demás generaciones y por ello hay que sospechar que se trata de fenómenos de variación inducida por contacto, sobre todo porque no se encuentran en el español no malecu y porque la gramática del idioma malecu actúa muy probablemente como detonante y refuerzo de un proceso de cambio. El empleo de 'dice/ dicen' como marcador de evidencialidad en los relatos tambín ejemplifica un muy probable caso de convergencia. A este nos referiremos con detalle más abajo.

Por último, la presencia de formas no normativas como 'haiga' y varias conjugaciones verbales regularizadoras (sea en términos de eliminar irregularidades particulares o más bien en términos de interpretar un determinado verbo como perteneciente a un paradigma irregular) rurales o con poca presión de la acción normativa escolar y social (Agüero, 2009; Arroyo, 1971; Quesada, 2009), sin que medie entonces participación de la lengua malecu y sin que se trate de fenómenos interlengua, como sí ocurre con las conjugaciones idiosincráticas presentes en el habla de los ancianos.

4.1.2.1. Análisis detallado de dos fenómenos morfosintácticos inducidos por contacto

A modo de ejemplo de la argumentación requerida $-\mathrm{y}$ que desarrollamos en otros trabajos con respecto a fenómenos muy puntuales: Sánchez, en prensa, a, b- para mostrar el posible origen de un cambio inducido por contacto de lenguas, nos referiremos brevemente a dos fenómenos morfosintácticos particularmente interesantes en el español malecu: el empleo oducir adjunto pes de dirección o destino, y el uso de 'dice/ dicen' como marcador de evidencialidad en las narraciones.

\subsection{La preposición 'en' como introductora}

de la noción de destino o dirección

La preposición 'en' muestra un empleo sistemático particular -incluso entre hablantes jóvenes- en el español malecu (distinto al español costarricense no malecu) con valor de dirección o de movimiento hacia un destino o de término del movimiento.

Los siguientes son ejemplos documentados en el habla de los ancianos y adultos mayores de los tres poblados: 'si yo voy en el centro de San José', 'yo fui en el departamento presupuestario', 'cuando yo fui la primera vez en la escuela', 'cuando yo llego / en Tonjibe ahí paso', 'yo me recuerdo que yo iba aquí: / hasta allá en Palenque Margarita / es un trillito así / mucho barrial / y nosotros vamos allá / en Palenque Margarita a recibir clases', 'vamos a pasear en Palenque Margarita', 'yo tuve que llevarlo en una camilla hasta allá: en Guatuso', 'ya llegamos en la casa', 'cuando llegamos nosotros en la casa'. En el habla de los jóvenes de dos de las comunidades registramos los siguientes ejemplos: 'después llegué aquí en Tonjibe', 'cuando nosotros llegamos en el colegio', 'yo fui en Guatuso', 'los malecus iban en la casa de ellos'.

El uso de 'en' con valor de movimiento no es desconocido en español. De Bruyne (2000, p. 669) la considera "una preposición de coincidencia espacial en sentido amplio" y afirma que, pese a que con verbos de movimiento tiende a aparecer ' $a$ ' y que "absolutamente inusual hoy es una construcción como ir en casa de alguno por ir a cada de alguno", reconoce que se documenta este valor en español antiguo y que perdura aún en "el habla popular y rústica".
Además, con los verbos que implican la noción de penetración (como 'entrar' y 'meter(se)'), De Bruyne asevera que en el español americano se prefiere el uso de 'a', mientras que en el peninsular es más frecuente 'en'. Finalmente, señala que ambas preposiciones compiten cuando se expresa la noción locativa pero en relación con un verbo que expresa movimiento, como en 'la fue a despedir al aeropuerto' o 'quiero invitarte a dormir a mi casa'.

En su detallado estudio de la oposición, alternancia y solapamiento de valores entre ' $a$ ' y 'en', López (1970, p. 164) asevera que "pueden neutralizarse en aquellas situaciones en que EN no indica propiamente un espacio cerrado, sino una superficie abierta", como en "hay vendedores a/en ambos pueblo' o 'se metió al/en el camino'. Esta autora agrega que en el español del Siglo de Oro eran más frecuentes las trasposiciones entre ambas y cita un ejemplo de Cervantes: 'aquel amigo que vivía a San Juan'.

Quesada (2009:294) encuentra ejemplos del valor direccional de 'en' en documentos coloniales de Costa Rica, como en el siguiente de 1731: 'oi no fui en casa de la dicha doña Josefa a preguntarle si me conpravan o no [...] estan recusados por ser familiares de la casa pues asisten todo el año en la casa de la susodicha'. Añade este lingüista que este valor se encuentra también en el español hablado por los bruncas de Costa Rica y consigna los ejemplos 'voy en San José' y 'llegamos en Palmar', pero considera más probable que se trate de 'un rasgo reliquia del español' que una innovación inducida por contacto (debido a que la lengua brunca diferencia formalmente la noción locativa de la direccional mediante dos posposiciones distintas).

No obstante, Quesada (2009, p. 294) acepta la posibilidad de una doble causación, "en donde se conjuga la influencia de una lengua indígena más un rasgo antiguo del castellano", tomando en cuenta que el fenómeno se ha documentado en otras regiones hispanohablantes y que de Granda (1994) lo registra para el español paraguayo como un posible rasgo de convergencia. En efecto, de Granda (1994, p. 333) apunta lo siguiente:

En el español del siglo $X V I$ existía aún la posibilida de emplear con verbos de direccionalidad la

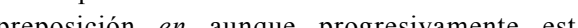
preposición en aunque progresivamente esta tilizaba para esta función, la proposión a utizzaba, para esta función, la preposición a y de verbos de permanencia A diferen de lo ecriós de permanencia. A diferencia de lo que cscásin el espanol general en el que, saluo escasisinas excepciones, triunfo la alternativa direccion es y de en con verbos a cermen local, el espãol paraguayo del siglo XVI cleccióé la posibilidag án viente enton le manejer para las dos funciones (permances, y direccionalidad los fues) la preposición caccosion en lengua en ello, un rasgo homólogo del guaran

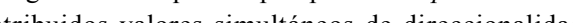
y permanencia locales.

El valor de dirección o destino de 'en' no está reportado para ninguna variedad del español costarricense, con excepción de "entre los indígenas de Costa Rica" según Quesada (2000, p. 96). Si bien en el caso del españo hablado por los bruncas probablemente no se trate de un fenómeno de convergencia, en el caso del español hablado por los malecus no habría otra explicación: si tomamos en cuenta que el valor direccional de 'en' se empezó a perder en español a partir del siglo XVI y que el contacto con este idioma comenzó entre los malecus finales del XIX, es poco probable que se trate de una "reliquia".

Más bien, todo apunta a que se puede considerar un cambio inducido por contacto, aprovechando un ámbito en el que la distribución de los valores de las preposiciones 'a' y 'en' ha sido históricamente inestable y sigue siéndolo para determinados verbos (como los de penetración). La lengua malecu expresa tanto el valor locativo como el alocativo con la posposición $\boldsymbol{c o}$, como se aprecia en los siguientes ejemplos consignados por Constenla (1998, p. 107): tíco ipunh 'está en el agua', itiónhe úco 'entró a la casa', a los que le podemos agregar un tercero para mostrar precisamente el valor que no coincide con el español no malecu: itóye naúco 'él fue a mi casa'. 
4.1.2.1.2. Uso de 'diceldicen' como marcador de evidencialidad en las narraciones

Otro fenómeno particular del español malecu que examinaremos aquí consiste codificación por medios léxico-gramaticales del modo en que el hablante obtuvo o tuvo acceso a la información: evidencia directa o encia indirecta referida por otros o una colectividad anónima (como ocurre con la tradición oral) o evidencia indirecta inferida (Speranza, 2014). Dentro de esta perspectiva, se puede observar que, en las narraciones tradicionales en malecu, uno de los rasgos formales más comunes consiste en utilizar el verbo $q u i$ 'decir' como marcador de evidenciatidad, et cual el cual además deben conjugarse "todos los verbos cuando se

"iquí nícacáf ianhé

lacá ní rricuanh maráme Tós lacá lha.

quí nán iquí chiúti inhánhe, os blancos,

iquí nán iquí nícaní iconh-îlh ní yu acá ó Tócu maráma

iquí nán iquí epém ésa orróqu rricanhé en la marcación de la evidencialidad en los relatos. Por evidencialidad entendemos la mplean para referirse a acontecimientos que de hecho han sucedido o están sucediendo" (Constenla, 1985, p. 44)

El texto se caracteriza habitualmente como narración de hechos no presenciados por el narrado por medio de la forma verbal iquí 'dice' (i- 'tercer persona', quí 'decir') que puede repetirse un númer indeterminado de veces a los largo del mismo. La tercera persona de la forma verbal en cuestió parece aludir a la narración misma (...). (Constenla, Castro y Blanco, 1993, p. 20)

A modo de ejemplo, así comienza uno de los relatos cosmogónicos transcritos y traducido por Constenla (Constenla, Castro y Blanco, 1993 p. 71); al lado de cada enunciado agregamos la traducción libre al español modificada levemente de la versión más literaria que realiza Constenla (Constenla, Castro y Blanco, 1993, p. 123), con el propósito de que se pueda apreciar mejor la marcación de la evidencialidad:

dice sucedió cierta vez

dice pues dice tenía mucha barba esto le sucedió con los Dioses

dice pues dice no les comía nad

a los malecus."

hí para ir a San Carlos / para abajo un poco / y dicen que los huleros / cuando llegaba aquí ((ves)) palabra que yo ni lo vi/ tambien calpable de de de pobres huleros viene / va un flechazo / en el pecho / fijate / dicen que lo mataron /

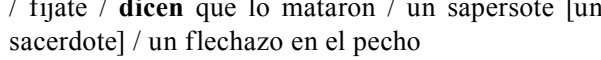

El siguiente es un relato del mismo hablante acerca de una experiencia personal:

y. sí / conmigo / yo andaba / yo estaba jovencito
/ yo fui a montear / con otro / tres / tres amigos / uno hermano mío y un amigo / bueno / y ya perro buscando / sajíno / ya / ese es bueno pa el saíno / ya /y ahí nomás / cuando ya latió el perro / caen caen caen / y fuimos allá donde / donde gritaba el perro / está muerto / todo lo majaba la cabeza / y es un alimalón tigre / así era la cabeza / pero lo matamos nosotros / iqué alimalón! / es ahí nomás / en en en / Cucaracha

Nótese cómo el primer relato (una narración de un acontecimiento en el que el narrador no participó, propio de la tradición oral; es decir, un relato de evidencia indirecta oral; es decir, un relato de evidencia indirecta
referida) incluye las formas 'dice' y 'dicen', referida) incluye las formas 'dice 'y 'dicen', acontecimiento en el que sí participó; esto es, un relato de evidencia directa o de primera mano) no se emplea ninguna de ellas. El siguiente relato se recogió de una adulta mayor de El Sol, quien cuenta una experiencia en la que ella no participó y que muestra el mismo empleo de 'dice' como marcador de evidencialidad:

dice que a veces / un día de estos dice que estuvieron ahí / yo no sé por dónde / cierta parte

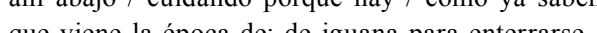
de poner huevitos/ahora en marzo ya empiezan a de poner huevilos/ahora en marzo ya empiezan a gente / dicen que bajaron iguana / y se tuvieron que esconder con todo el saco de iguana dice

Para el español costarricense sin influjo de una lengua amerindia, Constenla (1985), en su análisis de dos extensos relatos orales tradicionales de un narrador campesino, encuentra un empleo muy abundante de formas del verbo 'decir' en tercera persona del presente de indicativo con la función de "evitar posibles confusiones entre las palabras del narrador y las palabras de otras personas citadas por él" (Constenla, 1985, p. 43)

Asimismo, es frecuente -al menos en malecu, al menos en el habla de los bilingües con el malecu como lengua dominante y en el un relato de un anciano de Margarita sobre un acontecimiento que no él no presenció: pues dicen que huleros vienen / aquí / Nicaragua en
bote / y aquí casa bien / pues (d)onde (a)hora camino otra persona que se lo relató al “dijo" el participante de la historia Este fenómeno no estudiado con detalle en las variedades introduzca algunas de las clóusul narrad del español costarricense- se puede interpreta como un tipo de codificación discursiva de la evidencialidad. Así se aprecia con claridad en el siguiente relato de un adulto de Margarita:

la maestra mía / me refiero a la maestra E. / que era / ella fue mi maestra / que dice que cuando la primera vez que ella llegó aquí / dice que ella er de El Silencio / mas o menos por / como a unos do tice que habí un puente por de ahí vela a C. (..)

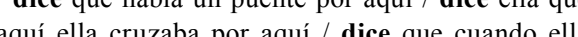
se topaba a esos indios todavía en taparrabos / persona que estaba con flechas / dice que ella estab asustada porque creía que lo iban lo iban a saetear

Por consiguiente, dado que el uso de 'decir' en los relatos forma parte de la estructura narrativa tradicional del español, con la función de introducir el discurso directo y -lo que más nos interesa aquí- para relatar experiencias que el narrador no vivió sino que se las contaron, el hablante malecu aprovecha este recurso formal y lo emplea para codificar la evidencialidad en las narraciones (posibilidad ya de por sí disponible también en español con estructuras del tipo 'dicen que...' y 'me contaron que...), al estilo de lo que se hace en la lengua malecu. Es decir, estamos ante un muy posible ejemplo de convergencia que lleva a que en el español hablado por algunos malecus se extiendan las posibilidades de empleo de un recurso formal del español no malecu con la finalidad de distinguir los relatos de vivencias personales (evidencia directa) frente a los relatos de acontecimientos no presenciados (evidencia indirecta relatada), como ocurre en malecu.

Así, cuando un relato se refiere a una experiencia no vivida por el narrador, se introducen las formas 'dice' y 'dicen' cada tanto en español al estilo de la narración en malecu como marcas de evidencialidad no directa, sin que con ello se marquen ni turnos conversacionales ni la introducción de un discurso directo (como en las narraciones del anciano de Margarita y del adulto mayor de El Sol), o bien este recurso sirve tanto para indicar que no se narra una experiencia para indicar que no se nara una exp personal como para citar de forma general las la narración del adulto de Margarita) ${ }^{12}$. 


\subsubsection{Rasgos léxicos}

En lo relativo al léxico, de nuevo encontramos tres orígenes para las particularidades en nuestros datos: rubros léxicos que corresponden a localismos hispánicos de la región o de los grupos con los que los malecus han mantenido un contacto histórico prolongado e intenso, neologismos de interlengua, y malequismos con distintos grados de adaptación al español.

Ejemplos de regionalismos son el verbo 'afrentarse' por 'avergonzarse', registrado por Quesada (2007) como guanacastequismo (con la variante 'efrentarse' en el habla de algunos malecus, tratado como verbo con irregularidad de diptongación o no: 'se afrentan', 'se efrientan', 'se efrentan'), y 'dilatar' por 'tardar', registrado por Quesada (2007) como propio del noroeste de Costa Rica y de zonas rurales del Valle Central, además de otras formas propias del habla rural como 'creyencias' y 'dentrar' (Quesada, 2007).

Los neologismos de interlengua son propios únicamente de los ancianos. Entre ellos encontramos 'con cabo' con el sentido de 'al final' ('con cabo no / no es el legítimo malecu'), 'un tiempo' por 'una vez' o 'hace tiempo' ("un tiempo me dijo mi hija / que "usted está hablando"'), 'los nuevos' o 'los que van a venir de nuevo' por 'los jóvenes, las nuevas generaciones' ('lo que va a venir de nuevo ellos lea / eso'), 'el año tras año' por 'hace años' ('te voy a contar una historia de de del año tras año'). Muchos de estos neologismos no están consolidados ni trascienden más allá de la situación concreta en que fueron creados por el hablante con el fin de comunicarse.

Por último, es común que los malecus de todas las edades inserten malequismos en su discurso en español y de alternancia de códigos. Si bien la mayoría de los términos tienen que ver con entidades o nociones propias de la cultura tradicional malecu o de su literatura oral, por lo que no existe un equivalente de traducción exacto en español (así ocurre, por ejemplo, con muérra 'un tipo de gigante peludo', mafuriséca 'un tipo de alimento asado', chiúti 'persona no malecu'), muchos otros sí cuentan con un equivalente en español (por ejemplo, turrúcu 'pareja', tócu 'Dios', táfa 'felino, tigre', púpa 'jícara', ulima 'tortuga', érra 'iguana', múju 'pescado', cajúli 'café, cáju 'cacao', júma 'pejibaye', jút, 'aguacate), pero por lo común se refieren objetos, animales o plantas particularment relevantes en la cultura malecu.

Así, en la entrevista a una adulta documentamos enunciados con varios malequismos como 'excepto la martilla ¿verdad? / yo como érra [iguana] / lenhifa [armadillo] / múju [pescado] / el mono colorado' [alla solo mamjéca [cocina]//as digamos. "ella solo mamjeca [cocinar] / así digamos'. Y de un joven documentamos un enunciado como 'hay una del táfa [tigre] / el muérra [ogro] / eh caracche [duente] / hay muchos' y 'te va a llevar el caracche'. De un niño de tres años registramos en habla espontánea el enunciado 'ayer chocó un píli [tucán] ahí (en la ventana)'.

El grado de adaptación de los malequismos a la fonología y la gramática del español es muy variable. Así, de una misma anciana tenemos ejemplos no adaptados en absoluto como 'yo le di mulhúó [pescadito] pero no quiso', en el que se emplea el término malecu mulhú con el marcador de diminutivo ó también en malecu, y 'esa ulimita [tortuguita] se la regalé a ella', en que se emplea la raíz ulíma con el sufijo diminutivo del español.

A este respecto, quizás los malequismos que muestran mayor variabilidad son 'malécu' y 'chiúti', pues aparecen con el morfema de plura -s o sin él indistintamente en un mismo hablante, aunque en este caso en particular pareciera que la hispanización morfológica de estas dos palabras es más propia del habla de los adutos y los jóvenes: '¿por qué los chiúti tiene que supervisar?', 'yo vi / las dos malecu hablando en malecu', 'el malecu se ha se ha se ha dado respetar / ante los chiútis', 'yo me enteré de eso por bocas de: / de otros malecus', 'ella se imagino que nosotros los malecu le podemos hacer algo (...) porque mami dijo que no / las personas malecus no eran tan malos así como como hay en otros lugares'.

\section{Reconocimiento del español malecu}

\section{como variedad particular}

De acuerdo con Wölck (2009), lo más importante con respecto a un etnolecto es que se trata de una variedad idiomática de una lengua mayoritaria (pero no radicalmente distinta a esta) cuyo origen se relaciona con una situación de bilingüismo social y que es interpretada por el exogrupo como marcador de etnicidad. Así, este autor caracteriza los etnolectos como variedades lingüísticas delimitadas por los siguientes criterios:

1. existía en el pasado reciente (hace menos de tres generaciones) un bilingüismo activo en la comunidad; 2. las comunidades son bien definidas, estables y contiguas, 3 . la comunicación rasgos etnolectes es an estereotipados y (tal vez) estigmatizados por los de fuera de la comunidad; 4 algunos rasgos son (todavía) usados como indicadores sociales. (Wölck, (todavía) usad p.164).

Claramente, como vemos, en el caso malecu se cumplen las condiciones 1,2 y 3 (en lo que respect a $\mathrm{y}$, si bien no hemos seguido la metodología propuesta por Wölck, sí intentamos explorar si se cumple la segunda parte de la condición 3: el reconocimiento de la existencia de una variedad de español malecu por parte de los miembros del grupo hispanohablante no malecu de la región de Guatuso, sin tomar en cuenta la condición 4, pues Gut

Para tal efecto, se le preguntó a una muestra selectiva accidental de 89 individuos hispanocostarricenses en el pueblo de San Rafael de Guatuso (el centro de comercio, servicios e instituciones públicas más importante del cantón y del distrito donde se ubica el territorio malecu) si se consideraban capaces de reconocer el origen malecu de una persona por su manera de habla español ${ }^{13}$.

Para ello se les pidió que mostraran su acuerdo o desacuerdo con respecto a la proposición "Yo puedo reconocer que alguien es malecu por la forma como habla esp inl". La mayoría de los encuestados (un 67,4\% si se suma el 50,5 de totalmente acuerdo y el $16,9 \%$ de parcialmente de acuerdo) afirma poder reconocer a los malecus utilizando este criterio lingüístico. No obstante, es claro que la percepción de que dicha variedad existiría no es unánime, como lo indica la cifra de quienes rechazaron, total $(20,2 \%)$ o parcialmente $(11,2 \%)$, la proposición $(31,4 \%)$

Además, se recogieron datos por medio de la pregunta abierta "Cuando un malecu habla español, ¿a usted cómo le suena?", los cuales refuerzan lo que hemos señalado. Al respecto, predominan los comentarios generales dirigidos a indicar que se trata de una variedad idiomática ("diferente", "anomal", "un poco ravo"). En ("diferente", "anornal", "un poco raro"). E particular, se mencionan diferencias sobre todo de pronunciación ("el acento que no es igual", "tienen como un acento diferente", "ellos se comen algunas letras", "las palabras son algo cortadas"). Aunque escasas, también se recogieron algunas alusiones relativas al léxico ("cambian algunas palabras" "se les enredan la palabras") y a la gramática ("a veces conjugan los verbos mal: yo ir")

En cuanto a las causas, algunas veces se atribuye la diferencia a la interferencia de la lengua malecu o a la alternancia/mezcla de códigos ("es un español revuelto con el malecu"), pero lo más común es que se dé a entende que se trata de un español aprendido como segunda lengua ("como los gringos cuando están aprendiendo a hablar español"). No obstante, se señala también que dicha variedad "peculiar" de español es característica más bien de las generaciones mayores, mientras que ya en los jóvenes no se nota tanto la diferencia ("los más viejitos / los jóvenes no"). De hecho, una de las encuestadas fue enfática al respecto: "me baso en el malecu no estudiado, que no ha llegado al colegio, son los viejos de antes, señores de 70, 80 años, indígena viejo viejo, que no tuvo oportunidad ni siquiera de ir a la escuela, los chiquillos se expresan mejor".

Son escasos los ejemplos concretos que los encuestados proporcionaron. En lo que respecta a rasgos morfosintácticos, se recogieron casos de asignación no canónica del género 
de los sustantivos ("dicen la mapa", "dicen la río"), un error en la escogencia del rubro léxico ("mucho error / ejemplo del español que hablan / yo pregunté "¿cómo siguió su esposo?" y me respondió "el Señor me lo partió hace días") y dos rasgos fonológicos: la elisión de las vocales in [h] de $/ x /$ (") h] de $/ \mathrm{x} /$ ("una le jarran taques' por 'al chiquito le agarran ataques"”). Cuando se les presentaron varios enunciados con fenómenos que aparecen en los ejemplos consignados junto a otros inventados y no presentes en el habla de los malecus, los encuestados fueron incapaces de discernir entre las formas malecus y las no malecus.

En cuanto a la valoración de los propios malecus acerca de su variedad de español, es común que los jóvenes indiquen que el habla de los ancianos es distinta, pero no solo en relación con la de los no malecus, sino en particular con respecto a la suya propia. Es decir, no consideran que exista algo así como un español malecu, sino que el habla de los ancianos presenta fenómenos propios de quienes aprenden el español como segunda lengua. Así, los jóvenes de Margarita lo describen como un español "enredado" o incluso llegan a afirmar que llegaron a conocer a algunos ancianos que "no sabían hablar muy bien español" o que "no dominan muy bien", para lo cual aducen el ejemplo "¿usted ha visto las películas que hablan así como: / "yo llamarme"? / así".

También los jóvenes de El Sol indican que a esos ancianos "costaba entenderles" y los adultos de El Sol lo describen del siguiente modo: "le pasa a los gringos / que hay unos que no pueden hablar bien el español / o sea / viene siendo parecido", "por ejemplo ellos quiere decir "nosotros no sabemos" y a veces ellos dicen "nosotros no saber" o "no saben" / "nosotros no saben"'. En todos los casos se insiste en que el habla de los adultos por lo general no es así.

En nuestro corpus, solamente en los grupos de adultos y jóvenes de El Sol se comentaron las posibles interferencias del malecu en el español hablado por las generaciones más jóvenes (y con un bilingüismo equilibrado o incluso subordinado a favor del español) como consecuencia de la situación de contacto lingüístico prolongado. La conciencia más clara de las posibles interferencia la expresa el siguiente adulto, quien sí considera que todavía en las generaciones jóvenes se encuentra un habla malecu diferenciada:

a veces yo he visto / también no sé digamos / con personas de la misma edad mía ¿verdad? / que: hay palabras que uno / tal vez yo lo noto / de que no ne está hablando de la forma correcta en españo / porque tenemos este / el dialecto de nosotros ¿verdad? / que es el malecu/ y entonces hay palabras cue tal vez que que / que yo lo digo en españo / según yo estoy pensando de que lo digo de la mejo manera ¿verdad? / pero no no lo digo de la form correcta jverdad? / sinceramente yo digo que es también / depende digamos / porque tenemos otro otro dialecto.

En conclusión, si bien se puede suponer que existe reconocimiento parcial de la existencia de algo así como un "español malecu" en el caso de los hispanocostarricenses de la región Guatuso, que sí podrían reconocer a un malecu por su forma de hablar español, debe entenderse que se trata de una percepción global (tal vez muy ligada al componente fonético) y que, con excepción quizás del empleo de verbos en infinitivo en lugar de verbos conjugados, no existe conciencia clara acerca de cuáles son los rasgos particulares lecus mayoritariamente no reconocen así, sino que aducen que solo en los ancianos se halla un español distinto.

\section{Conclusiones}

El español hablado por los malecus se caracteriza por tres rasgos básicos: a) la presencia de fenómenos y rasgos que lo vinculan con el español del noroeste de Costa Rica y con el sur de Nicaragua, así como de rasgos rurales hispanocostarricenses; b) en el caso del habla de los ancianos, la existencia de fenómenos propios de una interlengua: múltiples vacilaciones, neologismos, interferencias de lengua materna y fosilizaciones; y c) la presencia de algunos fenómenos que muestran vigencia intergeneracional y que muy probablemente sean causados por el contacto de lenguas (cambios indirectos inducidos por contacto y préstamos). En lo relativo a la primera característica, se encuentra la aspiración y elisión de /-s/ implosiva, la realización vibrante múltiple de /r/ (fenómeno con toda probabilidad reforzado por la lengua malecu) y algunos elementos léxicos como 'afrentarse'. Estos rasgos, los cuales contrastan con la variedad extendida en el Valle Central, sin duda provienen del primer contacto duradero que tuvieron los malecus con un grupo hispanohablante: los nicaragüenses que habían entrado en la región durante la época de la extracción del hule y que se asentaron posteriormente al norte del territorio malecu. No puede obviarse tampoco que muchos malecus han establecido relaciones de pareja con individuos de origen nicaragüense.

Por su parte, los rasgos idiomáticos característicos de zona rural se explican por los poblamientos posteriores de campesinos vallecentraleños que se ubicaron alrededor de los palenques y dentro del mismo territorio, sobre todo en las décadas de 1970 y 1980 , con quienes desde entonces ha habido un contacto continuo y frecuente. De ellos posiblemente provienen elementos tipificados como rurales. Así, el español hablado por los malecus revela de alguna manera la historia de las migraciones hispanas a la región.

Algunos rasgos frecuentes y "sui géneris" del español hablado por los malecus podrían deberse al contacto lingüístico prolongado entre el español y el malecu: la concordancia ad sensum extendida con sustantivos colectivos como 'gente' en todas las generaciones; construcciones del tipo '(a) los jóvenes le dan vergüenza hablar malecu', en las que el dativo se interpreta como sujeto y la concordancia verbal se establece con este, también registradas en hablantes de todas las edades; el uso de frases preposicionales con 'para' en función de objeto indirecto y de 'en' con valor de destino; y la confluencia de pronombres y formas verbales de segunda persona 'vos' con las de segunda persona 'usted', del tipo "¿qué te pasa a usted?" y “¿para qué usted me pediste eso?”.
Por último, los rasgos de interlengua (sin que ello implique necesariamente interferencia de la estructura de la lengua malecu, pues muchos muestran la variación en el proceso de adquisición de una lengua) son propios únicamente de los ancianos y algunos adultos mayores, quienes adquirieron el español como segunda lengua en edad relativamente avanzad y casi siempre de modo natural (con poca nula intervención de la escuela), lo que explica las múltiples fosilizaciones. Por ello, su habla se caracteriza por múltiples fenómenos no encontrados en variedades del español sin influjo de una lengua indígena ni en hablantes nativos del español de Costa Rica.

En términos intergeneracionales, se podría decir que el habla de los ancianos muest ra las posibilidades máximas de innovación, mientras que el habla de los jóvenes revela la mínima variación con respecto al español no malecu, con apenas algunos fenómenos, pero ya en retroceso muy probablemente por acción de comunica

Así, en las en las que el bilingin equilib que el bilingüismo malecu-español es equilibrado (aunque no siempre simultáneo) o en las que el español se ha convertido en la lengua dominante (e incluso única para los monolingües o cuasimonolingües), encontramos algunos estos casos, variantes de desarrollo. En realidad, estamos ante posibles cambios indirectos inducidos po contacto (en el caso de algunos fenómenos gramaticales) y préstamos (en el caso del léxico) en los que generalmente se ha reforzado o se ha ido un paso más allá en un cambio lingüístico en ciernes en español.

En cuanto a los rasgos documentados durante el siglo $\mathrm{XX}$, hay que recalcar que se registran en el habla de los actuales ancianos el empleo de verbos en infinitivo en lugar de verbos conjugados, la elisión de vocales iniciales de palabra, las discordancias de elementos nominales, y, en un caso, la realización $[\mathrm{h}] \mathrm{de} / \mathrm{g} /$. Es decir, con toda seguridad el español hablado por los malecus -de todas las edades- hace 
más de medio siglo se habría caracterizado por mayores interferencias de su lengua autóctona y más rasgos de desarrollo. Empero, la situación actual ha cambiado radicalmente en relación con la variable etaria.

Nuestra perspectiva en el presente trabajo ha sido de naturaleza exploratoria y cualitativa. El análisis detallado de los fenómenos morfosintácticos descritos, así como de otros no citados, se realiza, con toda la argumentación debida, en dos monografías: una acerca del empleo del clítico de objeto directo lo como archimorfema (Sánchez, 2015) y otra sobre cambios inducidos por contacto relacionados con las propiedades formales de codificación de los participantes del evento (Sánchez, a)

\section{Notas}

1. Esta investigación se desarrolló en el marco del proyecto internacional El español en contacto con otras lenguas: variación y cambio lingüistico, dirigido por la Dra. Azucena Palacios Alcaine de la Universidad Autonoma de Madrid y financiado parcialmente por el Ministerio de Economia y Competitividad de España (Ref. FFI2012-31702), y como proyecto inscrito en la Vicerrectoria de 745-B3-104). El a Universidad de Costa Rica (N

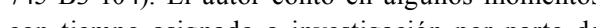
con tiempo asignado a investigación por parte de la Unive de la Universidad de Costa Rica y con la asignación

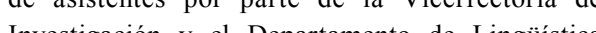
de la Universided de Costa Rica. Le agradezco al M. Henry Angulo la revisión de la treducción del resumen al inglés, y a los axistes Diego del resumen al inglés, $y$ a los asistentes Diego

colaboración para sistematizar algunos de los datos.

2. Particularmente útiles resultan los datos del Atlas lingüistico etnográfico de Costa Rica (ALECORI), elaborado bajo la coordinación de Quesada (2010). Sin embargo, en este no se registran datos del cantón de Guatuso, por lo cual hemos tenido que examinar la información de las regiones colindantes $y$ de

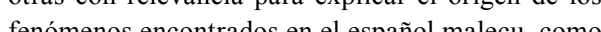
se verá más adelante.

3. No nos resultó posible identificar la frase 'naiála pun'
Dado que no realizamos análisis estadísticos de la frecuencia de los fenómenos, recurrimos a ambos o mayor presencia y prevalencia de los rascos en las distintas generaciones.

5. La palabra 'tamuga' está registrada como costarriqueñismo para 'conjunto de dos pares de tapas de dulce' (Quesada, 2007, p. 370)

6. En este hablante se registran fenómenos muy [arser también pronuncia [saser'dote]

Quesada $(1996,2008)$ informa de la existencia de este ultimo fenos que habitó la mayor parte del Valle Central de Costa Rica y cuya lengua autóctona se cree extinta desde el siglo XVIII. En particular, afirma que "los hablantes adultos de Zapatón agregan una /el en palabras cuyo sonido final es vibrante: güetar $\rightarrow$ güetare, llegar $\rightarrow$ llegare, comer $\rightarrow$ comere (Quesada, 1996, p. 95).

8. Quesada $(2009$, p. 88$)$ afirma que "a partir del siglo $\mathrm{XX}$, la variación vocálica pasa de general a local e traslada de la ciudad a zonas rurales, y del hable culta al habla popular, con lo cual, prácticamente en la época actual, dichos cambios se registran, salvo contadas excepciones, en boca del habitante de las áreas rurales"

9. Los datos del ALECORI (Quesada, 2010) muestran que en Upala, región colindante con el cantón de Guatuso, así como en Tilarán y Ciudad Quesada, zonas a las que los malecus acuden para transacciones comerciales o servicios, predomina realización fricativa alveolar, no la aspiración

10. Umaña (1990) encuentra apenas un total de $4,76 \%$ de realizaciones vibrantes múltiples de /r/ en un muestra de hablantes con formación universitari residentes de San José. Los datos del ALECOR Quesada, 2010) muestran que en Upala predomin la realización vibrante múltiple, mientras que en Tilarán y Ciudad Quesada predomina la realización fricativa o alternan ambas. Es decir, la realización vibrante es común en toda la región, de modo que la realización fricativa constitui adicionales, particularmente cuando los jóvenes bilingües traducen -de forma oral- los relatos de los ancianos, es particularmente frecuente esta utilización de 'dice'.

12. Resulta muy interesante que un patrón morfosintáctico similar se encuentre con frecuencia en el espanol con in thjo quechua y aimara de

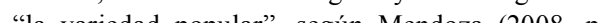
225) quien se refiere a él como "“dice' con función de validador referencial" o "función reportativa" y quien aduce que "estas formas son consideradas como equivalentes de los sufijos narrativos sqa del quechua o tayna del aimara" cuando se agregan al final de las oraciones, como en Le habia amenazado, dice; Ahora están pidiendo, diciendo, y Por eso está lloviendo harto, diciendo han dicho.

13. Véase Sánchez (2012) para información sobre el instrumento aplicado.

\section{Bibliografía}

Agüero, A. (2009). El español de Costa Rica. San José: Editorial de la Universidad de Costa Rica.

Alvar, M. (Ed.). (1996). Manual de dialectología hispánica. El español de América. Barcelona: Ariel Lingüística.

Appel, R. y Muysken P. (1996). Bilingüismo y contacto de lenguas. Barcelona: Ariel.

Arroyo, V.(1971). El habla popular en la literatura costarricense. San José: Publicaciones de la Universidad de Costa Rica.

Ballestero, R. (1952). Mi vida entre los guatusos. El maestro. I (8-9), 153-157.

Blas, J. (2008). Sociolingüistica del español. Desarrollos y perspectivas en el estudio de la lengua española en contexto social. Madrid: Cátedra.

Bosque, I. y Demonte V. (Eds.). (2000). Gramática Descriptiva de la Lengua Española. Madrid: Espasa Calpe.
Bozzoli, M. (1969). Localidades indígenas costarricenses. San José: EDUCA.

Buesa, T. y Enguita, J. (1992). Léxico del español de América: su elemento patrimonial indigena. Madrid: Editorial MAPFRE

Castillo, R. (2004). An Ethnogeography of the Maleku indigenous peoples in Northern Costa Rica. (Tesis doctoral). Universidad de Kansas.

Céspedes, A. (1923). Crónicas de la visita oficial y diocesana al Guatuso. San José: Imprenta Lehmann.

Constenla, A. (1975). La lengua guatusa fonología, gramática y léxico. (Tesis de licenciatura). Universidad de Costa Rica.

Constenla, A. (1985). Funciones del presente histórico en dos textos narrativos tradicionales costarricenses. Revista de Filología y Lingüística. 11(1), 41-61.

Constenla, A. (1988). El guatuso de Palenque Margarita: Su proceso de declinación. Estudios de Lingüistica Chibcha. 7, 7-37.

Constenla, A. (1998). Gramática de la lengua guatusa. Heredia: Editorial de la Universidad Nacional de Costa Rica.

Constenla, A. (2005). Algunos aspectos lingǘsticos y socioculturales de la influencia de las lenguas indígenas en las variedades americanas del español. Boletín de la Academia Costarricense de la Lengua. 1, 65-86.

Constenla, A. y Maroto, E. (1979). Leyendas y tradiciones borucas. San José: Editorial de la Universidad de Costa Rica.

Constenla, A., Castro, E. y Blanco, A. (1993). Laca Majifijica. La transformación 
de la tierra. San José: Editorial de la Universidad de Costa Rica.

De Bruyne, Jacques. (2000). Las preposiciones. Por I. Bosque y V. Demonte (Eds.). Gramática Descriptiva de la Lengua Española. (657-703). Madrid: Espasa Calpe.

De Granda, G. (1994). Español de América, español de Africa y hablas criollas hispánicas. Madrid: Gredos.

Escobar, A. y Wölck, W. (Eds.). (2009). Contacto lingüístico y la emergencia de variantes $y$ variedades lingüísticas. Madrid: Vervuert.

Hernández, L. (1996). Factores que influenciaron los cambios en la actividad productiva de pequeños productores del cantón de Guatuso. (Proyecto final de licenciatura). Universidad de Costa Rica.

Klee, C. y Lynch, A. (2009). El español en contacto con otras lenguas. Washington: Georgetown University Press.

Léglise, I. y Chamoreau, C. (Eds.). (2013). The Interplay of Variation and Change in Contact Settings. Amsterdam: John Benjamins Publishing Company.

Lininger, B. (1991). The Spanish of the SalitreCabagra Bribris: Internal Composition. (Tesis doctoral). The Florida State (Tesis doctor

Lipski, J. (1994). El español de América. Madrid: Cátedra.

López, M. (1970). Problemas y métodos en el análisis de preposiciones. Madrid: Gredos.

Mendoza, J. (2008). Bolivia. Por A. Palacios (Ed.). El español en América. Contactos lingüísticos en Hispanoamérica. (213236). Ariel: Barcelona.
Moreno, J. (1988). El español de América. México: Fondo de Cultura Económica.

Olbertz, H. y Muysken, P. (Eds.). (2005) Encuentros y conflictos. Bilingüismo $y$ contacto de lenguas en el mundo andino. Madrid: Vervuert.

Palacios, A. (Ed.). (2008). El español en América. Contactos lingüisticos en Hispanoamérica. Barcelona: Ariel.

Palacios, A. (2008). Introducción. Por A. Palacios (Ed.). El español en América. Contactos lingüisticos en Hispanoamérica. (11-15). Ariel: Barcelona.

Palacios, A. (2011). Nuevas perspectivas en el estudio del cambio inducido por contacto: Hacia un modelo dinámico del contacto de lenguas. Lenguas Modernas. 38, 17-36.

Palacios, A. (2013). Contact-induced change and internal evolution. Spanish in contact with Amerindian languages. Por I. Léglise y C. Chamoreau (Eds.). The Interplay of Variation and Change in Contact Settings. (165-198). Amsterdam: John Benjamins Publishing Company.

Porras, A. (1959). El idioma guatuso. (Tesis de licenciatura). Universidad de Costa Rica.

Quesada, M. (1990). El español colonial de Costa Rica. San José: Editorial de la Universidad de Costa Rica.

Quesada, M. (1991). El español de Guanacaste. San José: Editorial de la Universidad de Costa Rica.

Quesada, M. (1996). Los huetares: historia lengua, etnografía y tradición oral. Cartago: Editorial Tecnológica de Costa Rica.
Quesada, M. (2000). El español de América. Cartago: Editorial Tecnológica de Costa Rica.

Quesada, M. (2007). Nuevo diccionario de costarriqueñismos Cartago: Editorial Tecnológica de Costa Rica.

Quesada, M. (2008). América Central. Por: A. Palacios (Ed.). El español en América. Contactos lingüísticos en Hispanoamérica. (57-75). Barcelona: Ariel.

Quesada, M. (2009). Historia de la lengua española en Costa Rica. Editorial de la Universidad de Costa Rica: San José.

Quesada, M. (2010). Atlas lingüístico-etnográfico de Costa Rica (ALECORI). San José: Editorial de la Universidad de Costa Rica.

Salguero, M. (1969, 17 de agosto). A Cañas, con 800 pejibayes al hombro. La Nación, 36.

Sánchez, C. (2012). "Los indios lo que hablan es un dialecto". Representaciones de los hispanos con respecto a los malecus y su lengua vernácula. Revista de Filología y Lingüistica. 38 (2), 135-161.

Sánchez, C. (2011). Caracterización cualitativa de la situación sociolingüística del pueblo malecu. Estudios de Lingüistica Chibcha. 30, 63-90.

Sánchez, C. (2015). El sistema pronominal átono de tercera persona en el español hablado por los malecus de Costa Rica. Círculo de Lingüística Aplicada a la Comunicación. 61, 79-103.
Sánchez, C (a). Propiedades formales de codificación de participantes y cambio inducidos por contacto en el español hablado por los malecus.

Sapper, K. (1942). Viajes a varias partes de la República de Costa Rica 1899 y 1924. San José: Imprenta Nacional.

Speranza, A. (2014). Evidencialidad en el español americano. La expresión lingüistica de la perspectiva del hablante. Madrid: la perspecti

Ugalde, P. (1973). Guatuso. Un aporte a su estudio geo-económico y humano. (Tesis de licenciatura). Universidad de Costa Rica.

Umaña, J. (1990). Variación de vibrantes en una muestra del habla de clase media costarricense. Revista de Filología y Lingüistica. 16 (1), 127-137.

Wölck, W. (2009). Etnolectos americanos: Características y métodos de investigación Por: A. Escobar y W. Wölck (Eds.) Contacto lingüistico y la emergencia de variantes y variedades lingüisticas. (161171). Madrid: Vervuert.

Zamora, J. y Guitart, J. (1982). Dialectología hispanoamericana. Salamanca: Almar S.A.

Zimmermann, K. y Stolz, T. (Eds.). 2001 Lo propio y lo ajeno en las lenguas austronésicas y amerindias. Proceso. interculturales en el contacto de lenguas indigenas con el español en el Pacifico e Hispanoamérica. Madrid: Vervuert.

\section{(1) (1)}

Este obra está bajo una licencia de Creative Common 
